Convergence to common fixed point for a pair of quasi-nonexpansive mapping and asymptotically quasi-nonexpansive mapping in the intermediate sense

$$
\text { G. S. Saluja }
$$




\title{
CONVERGENCE TO COMMON FIXED POINT FOR A PAIR OF QUASI-NONEXPANSIVE MAPPING AND ASYMPTOTICALLY QUASI-NONEXPANSIVE MAPPING IN THE INTERMEDIATE SENSE
}

\author{
G. S. SALUJA
}

Received 24 September, 2013

\begin{abstract}
The purpose of this paper is to study modified two-step iteration process for a pair of quasi-nonexpansive mapping and asymptotically quasi-nonexpansive mapping in the intermediate sense. We also establish some strong convergence theorems and a weak convergence theorem for this iteration scheme and mappings in the framework of real Banach spaces. The results presented in this paper extend, improve and generalize some previous results from the existing literature (see for example [1,3, 5-7, 9-13]).
\end{abstract}

2010 Mathematics Subject Classification: 47H09; 47H10; 47J25

Keywords: asymptotically quasi-nonexpansive mapping in the intermediate sense, quasi-nonexpansive mapping, modified two-step iteration process, common fixed point, strong convergence, weak convergence, Banach space

\section{INTRODUCTION}

Let $K$ be a nonempty subset of a real Banach space $E$. Let $T: K \rightarrow K$ be a mapping, then we denote the set of all fixed points of $T$ by $F(T)$. The set of common fixed points of two mappings $S$ and $T$ will be denoted by $F=F(S) \cap F(T)$. A mapping $T: K \rightarrow K$ is said to be:

(1) nonexpansive if

$$
\|T x-T y\| \leq\|x-y\|
$$

for all $x, y \in K$.

(2) quasi-nonexpansive if $F(T) \neq \varnothing$ and

$$
\|T x-p\| \leq\|x-p\|
$$

for all $x \in K$ and $p \in F(T)$. 
(3) asymptotically nonexpansive if there exists a sequence $\left\{k_{n}\right\} \in[1, \infty)$ with $\lim _{n \rightarrow \infty} k_{n}=1$ and

$$
\left\|T^{n} x-T^{n} y\right\| \leq k_{n}\|x-y\|
$$

for all $x, y \in K$ and $n \geq 1$.

(4) asymptotically quasi-nonexpansive if $F(T) \neq \varnothing$ and there exists a sequence $\left\{k_{n}\right\} \in[1, \infty)$ such that $\lim _{n \rightarrow \infty} k_{n}=1$ and

$$
\left\|T^{n} x-p\right\| \leq k_{n}\|x-p\|
$$

for all $x \in K, p \in F(T)$ and $n \geq 1$.

(5) uniformly $L$-Lipschitzian if there exists a constant $L>0$ such that

$$
\left\|T^{n} x-T^{n} y\right\| \leq L\|x-y\|
$$

for all $x, y \in K$ and $n \geq 1$.

(6) uniformly quasi-Lipschitzian if there exists $L \in[1,+\infty)$ such that

$$
\left\|T^{n} x-p\right\| \leq L\|x-p\|
$$

for all $x \in K, p \in F(T)$ and $n \geq 1$.

Remark 1. It is clear that every nonexpansive mapping is asymptotically nonexpansive and every asymptotically nonexpansive is uniformly Lipschitzian. Also, if $F(T) \neq \varnothing$, then a nonexpansive mapping is a quasi-nonexpansive mapping, an asymptotically nonexpansive mapping is an asymptotically quasi-nonexpansive, a uniformly $L$-Lipschitzian mapping must be uniformly quasi-Lipschitzian and an asymptotically quasi-nonexpansive mapping must be uniformly quasi-Lipschitzian mapping but the converse is not true in general.

The class of asymptotically nonexpansive mappings was introduced by Goebel and Kirk [4] as a generalization of the class of nonexpansive mappings. Recall also that a mapping $T: K \rightarrow K$ is said to be asymptotically quasi-nonexpansive in the intermediate sense [17] provided that $T$ is uniformly continuous and

$$
\limsup _{n \rightarrow \infty} \sup _{x \in K, p \in F(T)}\left(\left\|T^{n} x-p\right\|-\|x-p\|\right) \leq 0 .
$$

From the above definitions, it follows that asymptotically nonexpansive mapping must be asymptotically quasi-nonexpansive and asymptotically quasi-nonexpansive mapping in the intermediate sense. But the converse does not hold as the following example: 
Example 1. Let $X=\mathbb{R}$ be a normed linear space and $K=[0,1]$. For each $x \in K$, we define

$$
T(x)=\left\{\begin{array}{cc}
k x, & \text { if } x \neq 0 \\
0, & \text { if } x=0
\end{array}\right.
$$

where $0<k<1$. Then

$$
\left|T^{n} x-T^{n} y\right|=k^{n}|x-y| \leq|x-y|
$$

for all $x, y \in K$ and $n \in \mathbb{N}$.

Thus $T$ is an asymptotically nonexpansive mapping with constant sequence $\{1\}$ and

$$
\limsup _{n \rightarrow \infty}\left\{\left|T^{n} x-T^{n} y\right|-|x-y|\right\}=\limsup _{n \rightarrow \infty}\left\{k^{n}|x-y|-|x-y|\right\} \leq 0
$$

because $\lim _{n \rightarrow \infty} k^{n}=0$ as $0<k<1$, for all $x, y \in K, n \in \mathbb{N}$ and $T$ is continuous. Hence $T$ is an asymptotically nonexpansive mapping in the intermediate sense.

Example 2. Let $X=\mathbb{R}, K=\left[-\frac{1}{\pi}, \frac{1}{\pi}\right]$ and $|k|<1$. For each $x \in K$, define

$$
T(x)=\left\{\begin{array}{cl}
k x \sin (1 / x), & \text { if } x \neq 0 \\
0, & \text { if } x=0
\end{array}\right.
$$

Then $T$ is an asymptotically nonexpansive mapping in the intermediate sense but it is not asymptotically nonexpansive mapping.

Since 1972, many authors have studied weak and strong convergence problem of the iterative sequences (with errors) for asymptotically nonexpansive mappings in Hilbert spaces and Banach spaces (see,for example, $[4,6,7,9-12,16]$ and references therein).

In 2007, Agarwal et al. [1] introduced the following iteration process:

$$
\begin{aligned}
x_{1} & =x \in K, \\
x_{n+1} & =\left(1-\alpha_{n}\right) T^{n} x_{n}+\alpha_{n} T^{n} y_{n}, \\
y_{n} & =\left(1-\beta_{n}\right) x_{n}+\beta_{n} T^{n} x_{n}, n \geq 1
\end{aligned}
$$

where $\left\{\alpha_{n}\right\}$ and $\left\{\beta_{n}\right\}$ are in $(0,1)$. They showed that this process converge at a rate same as that of Picard iteration and faster than Mann for contractions.

The above process deals with one mapping only. The case of two mappings in iterative processes has also remained under study since Das and Debata [3] gave and studied a two mappings process. Later on, many authors, for example Khan and Takahashi [6], Shahzad and Udomene [13] and Takahashi and Tamura [14] have studied the two mappings case of iterative schemes for different types of mappings. 
Recently, Khan et al. [5] studied the modified two-step iteration process for two mappings as follows:

$$
\begin{aligned}
x_{1} & =x \in K, \\
x_{n+1} & =\left(1-\alpha_{n}\right) T^{n} x_{n}+\alpha_{n} S^{n} y_{n}, \\
y_{n} & =\left(1-\beta_{n}\right) x_{n}+\beta_{n} T^{n} x_{n}, n \geq 1
\end{aligned}
$$

where $\left\{\alpha_{n}\right\}$ and $\left\{\beta_{n}\right\}$ are in $(0,1)$. They established weak and strong convergence theorems in the setting of real Banach spaces.

Inspired and motivated by Agarwal et al. [1], Khan et al. [5] and many others, in this paper we introduce the following iteration scheme for a pair of quasinonexpansive and asymptotically quasi-nonexpansive mapping in the intermediate sense. The proposed iteration scheme is as follows:

Definition 1. Let $S: K \rightarrow K$ be a quasi-nonexpansive mapping and $T: K \rightarrow K$ be an asymptotically quasi-nonexpansive mapping in the intermediate sense on a closed convex subset $K$ of a real Banach space $E$ with $K+K \subset K$. Let $\left\{x_{n}\right\}$ be the sequence defined as:

$$
\begin{aligned}
x_{1} & =x \in K, \\
x_{n+1} & =\left(1-\alpha_{n}\right) T^{n} x_{n}+\alpha_{n} S y_{n}+u_{n}, \\
y_{n} & =\left(1-\beta_{n}\right) x_{n}+\beta_{n} T^{n} x_{n}+v_{n}, n \geq 1
\end{aligned}
$$

where $\left\{\alpha_{n}\right\}$ and $\left\{\beta_{n}\right\}$ are sequences in $(0,1)$ and $\left\{u_{n}\right\}$ and $\left\{v_{n}\right\}$ are two sequences in $K$. The iteration scheme (1.3) is called modified two-step iteration process with errors for a pair of mappings.

The aim of this paper is to establish some strong convergence theorems and a weak convergence theorem for newly proposed iteration scheme (1.3) in the framework of real Banach spaces. The results presented in this paper extend, improve and generalize some previous known corresponding results from the literature (e.g. $[1,3,5-7,9-13]$ and many others).

\section{PReliminaries}

For the sake of convenience, we restate the following concepts.

A mapping $T: K \rightarrow K$ is said to be demiclosed at zero, if for any sequence $\left\{x_{n}\right\}$ in $K$, the condition $\left\{x_{n}\right\}$ converges weakly to $x \in K$ and $\left\{T x_{n}\right\}$ converges strongly to 0 imply $T x=0$.

A mapping $T: K \rightarrow K$ is said to be semi-compact [2] if for any bounded sequence $\left\{x_{n}\right\}$ in $K$ such that $\left\|x_{n}-T x_{n}\right\| \rightarrow 0$ as $n \rightarrow \infty$, then there exists a subsequence $\left\{x_{n_{k}}\right\} \subset\left\{x_{n}\right\}$ such that $x_{n_{k}} \rightarrow x^{*} \in K$ strongly. 
We say that a Banach space $E$ satisfies the Opial's condition [8] if for each sequence $\left\{x_{n}\right\}$ in $E$ weakly convergent to a point $x$ and for all $y \neq x$

$$
\liminf _{n \rightarrow \infty}\left\|x_{n}-x\right\|<\liminf _{n \rightarrow \infty}\left\|x_{n}-y\right\| .
$$

The examples of Banach spaces which satisfy the Opial's condition are Hilbert spaces and all $L^{p}[0,2 \pi]$ with $1<p \neq 2$ fail to satisfy Opial's condition [8].

Now, we state the following useful lemma to prove our main results:

Lemma 1 (see [15]). Let $\left\{\alpha_{n}\right\}_{n=1}^{\infty}$ and $\left\{\beta_{n}\right\}_{n=1}^{\infty}$ be two sequences of nonnegative numbers with $\sum_{n=1}^{\infty} \beta_{n}<\infty$. If one of the following conditions is satisfied:

(i) $\alpha_{n+1} \leq \alpha_{n}+\beta_{n}, n \geq 1$,

(ii) $\alpha_{n+1} \leq\left(1+\beta_{n}\right) \alpha_{n}, n \geq 1$,

then the limit $\lim _{n \rightarrow \infty} \alpha_{n}$ exists.

\section{MAin RESUlts}

In this section, we prove some strong convergence theorems and a weak convergence theorem of the iteration scheme (1.3) for a pair of quasi-nonexpansive and asymptotically quasi-nonexpansive mapping in the intermediate sense in the framework of real Banach spaces.

Theorem 1. Let $E$ be a real Banach space and $K$ be a nonempty closed convex subset of $E$ with $K+K \subset K$. Let $S: K \rightarrow K$ be a quasi-nonexpansive mapping and $T: K \rightarrow K$ be uniformly L-Lipschitzian asymptotically quasi-nonexpansive mapping in the intermediate sense such that $F=F(S) \cap F(T) \neq \varnothing$. Let $\left\{x_{n}\right\}$ be the sequence defined by (1.3) with the restrictions $\sum_{n=1}^{\infty}\left\|u_{n}\right\|<\infty$ and $\sum_{n=1}^{\infty}\left\|v_{n}\right\|<\infty$. Put

$$
G_{n}=\max \left\{\sup _{x \in K, q \in F}\left(\left\|T^{n} x-q\right\|-\|x-q\|\right) \vee 0, \forall n \geq 1\right\}
$$

such that $\sum_{n=1}^{\infty} G_{n}<\infty$. Then $\left\{x_{n}\right\}$ converges to a common fixed point of the mappings $S$ and $T$ if and only if $\liminf _{n \rightarrow \infty} d\left(x_{n}, F\right)=0$, where $d(x, F)=\inf _{p \in F} d(x, p)$.

Proof. The necessity is obvious. Thus we only prove the sufficiency. Let $q \in F$. Then from (1.3) and (3.1), we have

$$
\begin{aligned}
\left\|y_{n}-q\right\| & =\left\|\left(1-\beta_{n}\right) x_{n}+\beta_{n} T^{n} x_{n}+v_{n}-q\right\| \\
& \leq\left(1-\beta_{n}\right)\left\|x_{n}-q\right\|+\beta_{n}\left\|T^{n} x_{n}-q\right\|+\left\|v_{n}\right\| \\
& \leq\left(1-\beta_{n}\right)\left\|x_{n}-q\right\|+\beta_{n}\left[\left\|x_{n}-q\right\|+G_{n}\right]+\left\|v_{n}\right\| \\
& =\left(1-\beta_{n}\right)\left\|x_{n}-q\right\|+\beta_{n}\left\|x_{n}-q\right\|+\beta_{n} G_{n}+\left\|v_{n}\right\| \\
& \leq\left\|x_{n}-q\right\|+G_{n}+\left\|v_{n}\right\| .
\end{aligned}
$$


Again using (1.3), (3.1) and (3.2), we obtain

$$
\begin{aligned}
\left\|x_{n+1}-q\right\|= & \left\|\left(1-\alpha_{n}\right) T^{n} x_{n}+\alpha_{n} S y_{n}+u_{n}-q\right\| \\
\leq & \left(1-\alpha_{n}\right)\left\|T^{n} x_{n}-q\right\|+\alpha_{n}\left\|S y_{n}-q\right\|+\left\|u_{n}\right\| \\
\leq & \left(1-\alpha_{n}\right)\left[\left\|x_{n}-q\right\|+G_{n}\right]+\alpha_{n}\left\|y_{n}-q\right\|+\left\|u_{n}\right\| \\
\leq & \left(1-\alpha_{n}\right)\left\|x_{n}-q\right\|+\alpha_{n}\left[\left\|x_{n}-q\right\|+G_{n}+\left\|v_{n}\right\|\right] \\
& +\left(1-\alpha_{n}\right) G_{n}+\left\|u_{n}\right\| \\
\leq & \left\|x_{n}-q\right\|+G_{n}+\left\|u_{n}\right\|+\alpha_{n}\left\|v_{n}\right\| \\
= & \left\|x_{n}-q\right\|+\theta_{n}
\end{aligned}
$$

where $\theta_{n}=G_{n}+\left\|u_{n}\right\|+\alpha_{n}\left\|v_{n}\right\|$. Since by assumption of the theorem $\sum_{n=1}^{\infty} G_{n}<$ $\infty, \sum_{n=1}^{\infty}\left\|u_{n}\right\|<\infty$ and $\sum_{n=1}^{\infty}\left\|v_{n}\right\|<\infty$, it follows that

$\sum_{n=1}^{\infty} \theta_{n}<\infty$. Thus by Lemma 1 we know that the $\operatorname{limit}_{n \rightarrow \infty}\left\|x_{n}-q\right\|$ exists. Also from (3.3), we obtain

$$
d\left(x_{n+1}, F\right) \leq d\left(x_{n}, F\right)+\theta_{n},
$$

for all $n \geq 1$. From Lemma 1 and (3.4), we know that $\lim _{n \rightarrow \infty} d\left(x_{n}, F\right)$ exists. Since $\liminf _{n \rightarrow \infty} d\left(x_{n}, F\right)=0$, we have that $\lim _{n \rightarrow \infty} d\left(x_{n}, F\right)=0$.

Next, we shall prove that $\left\{x_{n}\right\}$ is a Cauchy sequence. Therefore, for any $m, n \geq 1$ and for given $p \in F$, from (3.3), we have

$$
\begin{aligned}
\left\|x_{n+m}-p\right\| & \leq\left\|x_{n+m-1}-p\right\|+\theta_{n+m-1} \\
& \leq\left\|x_{n+m-2}-p\right\|+\theta_{n+m-2}+\theta_{n+m-1} \\
& \leq \ldots \\
& \leq\left\|x_{n}-p\right\|+\sum_{j=n}^{n+m-1} \theta_{j} .
\end{aligned}
$$

Since

$$
\lim _{n \rightarrow \infty} d\left(x_{n}, F\right)=0, \quad \sum_{n=1}^{\infty} \theta_{n}<\infty
$$

for any given $\varepsilon>0$, there exists a positive integer $n_{1}$ such that

$$
d\left(x_{n}, F\right)<\frac{\varepsilon}{8}, \quad \sum_{j=n}^{\infty} \theta_{j}<\frac{\varepsilon}{4} \quad \forall n \geq n_{1} .
$$

Hence, there exists $q \in F$ such that

$$
\left\|x_{n}-q\right\|<\frac{\varepsilon}{4} \quad \forall n \geq n_{1} .
$$


Consequently, for any $n \geq n_{1}$ and $m \geq 1$, from (3.5), we have

$$
\begin{aligned}
\left\|x_{n+m}-x_{n}\right\| & \leq\left\|x_{n+m}-q\right\|+\left\|x_{n}-q\right\| \\
& \leq\left\|x_{n}-q\right\|+\sum_{j=n}^{n+m-1} \theta_{j}+\left\|x_{n}-q\right\| \\
& \leq 2\left\|x_{n}-q\right\|+\sum_{j=n}^{n+m-1} \theta_{j} \\
& <2 \times \frac{\varepsilon}{4}+2 \times \frac{\varepsilon}{4}=\varepsilon .
\end{aligned}
$$

This implies that $\left\{x_{n}\right\}$ is a Cauchy sequence in $E$ and so is convergent since $E$ is complete. Let $\lim _{n \rightarrow \infty} x_{n}=q^{*}$. Then $q^{*} \in K$. It remains to show that $q^{*} \in F$. Let $\varepsilon_{1}>0$ be given. Then there exists a natural number $n_{2}$ such that

$$
\left\|x_{n}-q^{*}\right\|<\frac{\varepsilon_{1}}{2(L+1)}, \forall n \geq n_{2} .
$$

Since $\lim _{n \rightarrow \infty} d\left(x_{n}, F\right)=0$, there must exists a natural number $n_{3} \geq n_{2}$ such that for all $n \geq n_{3}$, we have

$$
d\left(x_{n}, F\right)<\frac{\varepsilon_{1}}{3(L+1)},
$$

and in particular, we have

$$
d\left(x_{n_{3}}, F\right)<\frac{\varepsilon_{1}}{3(L+1)} .
$$

Therefore, there exists $z^{*} \in F$ such that

$$
\| x_{n_{3} \|-z^{*}}<\frac{\varepsilon_{1}}{2(L+1)} .
$$

Consequently, we have

$$
\begin{aligned}
\left\|T q^{*}-q^{*}\right\| & =\left\|T q^{*}-z^{*}+z^{*}-x_{n_{3}}+x_{n_{3}}-q^{*}\right\| \\
& \leq\left\|T q^{*}-z^{*}\right\|+\left\|z^{*}-x_{n_{3}}\right\|+\left\|x_{n_{3}}-q^{*}\right\| \\
& \leq L\left\|q^{*}-z^{*}\right\|+\left\|z^{*}-x_{n_{3}}\right\|+\left\|x_{n_{3}}-q^{*}\right\| \\
& \leq L\left\|q^{*}-x_{n_{3}}+x_{n_{3}}-z^{*}\right\|+\left\|z^{*}-x_{n_{3}}\right\|+\left\|x_{n_{3}}-q^{*}\right\| \\
& \leq L\left[\left\|q^{*}-x_{n_{3}}\right\|+\left\|x_{n_{3}}-z^{*}\right\|\right]+\left\|z^{*}-x_{n_{3}}\right\|+\left\|x_{n_{3}}-q^{*}\right\| \\
& \leq(L+1)\left\|q^{*}-x_{n_{3}}\right\|+(L+1)\left\|z^{*}-x_{n_{3}}\right\| \\
& <(L+1) \times \frac{\varepsilon_{1}}{2(L+1)}+(L+1) \times \frac{\varepsilon_{1}}{2(L+1)}<\varepsilon_{1} .
\end{aligned}
$$

This implies that $q^{*} \in F(T)$. Similarly, we can show that $q^{*} \in F(S)$. Since $S$ is 
quasi-nonexpansive, so it is uniformly quasi-1 Lipschitzian (by Remark 1), so here taking $L=1$, we have

$$
\begin{aligned}
\left\|S q^{*}-q^{*}\right\| & =\left\|S q^{*}-z^{*}+z^{*}-x_{n_{3}}+x_{n_{3}}-q^{*}\right\| \\
& \leq\left\|S q^{*}-z^{*}\right\|+\left\|z^{*}-x_{n_{3}}\right\|+\left\|x_{n_{3}}-q^{*}\right\| \\
& \leq\left\|q^{*}-z^{*}\right\|+\left\|z^{*}-x_{n_{3}}\right\|+\left\|x_{n_{3}}-q^{*}\right\| \\
& \leq\left\|q^{*}-x_{n_{3}}+x_{n_{3}}-z^{*}\right\|+\left\|z^{*}-x_{n_{3}}\right\|+\left\|x_{n_{3}}-q^{*}\right\| \\
& \leq\left[\left\|q^{*}-x_{n_{3}}\right\|+\left\|x_{n_{3}}-z^{*}\right\|\right]+\left\|z^{*}-x_{n_{3}}\right\|+\left\|x_{n_{3}}-q^{*}\right\| \\
& \leq 2\left\|q^{*}-x_{n_{3}}\right\|+2\left\|z^{*}-x_{n_{3}}\right\| \\
& <2 \times \frac{\varepsilon_{1}}{4}+2 \times \frac{\varepsilon_{1}}{4} \\
& <\varepsilon_{1} .
\end{aligned}
$$

This shows that $q^{*} \in F(S)$. Thus $q^{*} \in F$, that is, $q^{*}$ is a common fixed point of the mappings $S$ and $T$. This completes the proof.

Theorem 2. Let $E$ be a real Banach space and $K$ be a nonempty closed convex subset of $E$ with $K+K \subset K$. Let $S: K \rightarrow K$ be a quasi-nonexpansive mapping and $T: K \rightarrow K$ be uniformly $L$-Lipschitzian asymptotically quasi-nonexpansive mapping in the intermediate sense such that $F=F(S) \cap F(T) \neq \varnothing$. Let $\left\{\alpha_{n}\right\}$ and $\left\{\beta_{n}\right\}$ be sequences in $[\delta, 1-\delta]$ for some $\delta \in(0,1)$. Let $\left\{x_{n}\right\}$ be the sequence defined by $(1.3)$ with the restrictions $\sum_{n=1}^{\infty}\left\|u_{n}\right\|<\infty$ and $\sum_{n=1}^{\infty}\left\|v_{n}\right\|<\infty$. Put

$$
G_{n}=\max \left\{\sup _{x \in K, q \in F}\left(\left\|T^{n} x-q\right\|-\|x-q\|\right) \vee 0, \forall n \geq 1\right\}
$$

such that $\sum_{n=1}^{\infty} G_{n}<\infty$. Suppose that the mappings $S$ and $T$ satisfy the following conditions:

$\left(C_{1}\right) \lim _{n \rightarrow \infty}\left\|x_{n}-S x_{n}\right\|=0$ and $\lim _{n \rightarrow \infty}\left\|x_{n}-T x_{n}\right\|=0$,

$\left(C_{2}\right)$ there exists a constant $A>0$ such that

$$
\left\{\left\|x_{n}-S x_{n}\right\|+\left\|x_{n}-T x_{n}\right\|\right\} \geq A d\left(x_{n}, F\right)
$$

for all $n \geq 1$.

Then $\left\{x_{n}\right\}$ converges strongly to a common fixed point of the mappings $S$ and $T$.

Proof. From conditions $\left(C_{1}\right)$ and $\left(C_{2}\right)$, we have $\lim _{n \rightarrow \infty} d\left(x_{n}, F\right)=0$, it follows as in the proof of Theorem 1 , that $\left\{x_{n}\right\}$ must converges strongly to a common fixed point of the mappings $S$ and $T$. This completes the proof. 
Theorem 3. Let $E$ be a real Banach space and $K$ be a nonempty closed convex subset of $E$ with $K+K \subset K$. Let $S: K \rightarrow K$ be a quasi-nonexpansive mapping and $T: K \rightarrow K$ be uniformly L-Lipschitzian asymptotically quasi-nonexpansive mapping in the intermediate sense such that $F=F(S) \cap F(T) \neq \varnothing$. Let $\left\{\alpha_{n}\right\}$ and $\left\{\beta_{n}\right\}$ be sequences in $[\delta, 1-\delta]$ for some $\delta \in(0,1)$. Let $\left\{x_{n}\right\}$ be the sequence defined by $(1.3)$ with the restrictions $\sum_{n=1}^{\infty}\left\|u_{n}\right\|<\infty$ and $\sum_{n=1}^{\infty}\left\|v_{n}\right\|<\infty$. Put

$$
G_{n}=\max \left\{\sup _{x \in K, q \in F}\left(\left\|T^{n} x-q\right\|-\|x-q\|\right) \vee 0, \forall n \geq 1\right\}
$$

such that $\sum_{n=1}^{\infty} G_{n}<\infty$. Suppose $\lim _{n \rightarrow \infty}\left\|x_{n}-S x_{n}\right\|=0$ and $\lim _{n \rightarrow \infty} \| x_{n}-$ $T x_{n} \|=0$. If at least one of the mappings $S$ and $T$ is semi-compact, then the sequence $\left\{x_{n}\right\}$ converges strongly to a common fixed point of $S$ and $T$.

Proof. Without loss of generality, we may assume that $T$ is semi-compact. By Theorem 1, $\left\{x_{n}\right\}$ is bounded and by assumption of the theorem $\lim _{n \rightarrow \infty}\left\|x_{n}-S x_{n}\right\|=$ 0 and $\lim _{n \rightarrow \infty}\left\|x_{n}-T x_{n}\right\|=0$. This means that there exists a subsequence $\left\{x_{n_{k}}\right\} \subset$ $\left\{x_{n}\right\}$ such that $x_{n_{k}} \rightarrow x^{*} \in K$ as $n_{k} \rightarrow \infty$. Now again by the hypothesis of the theorem, we find

$$
\left\|x^{*}-T x^{*}\right\|=\lim _{n_{k} \rightarrow \infty}\left\|x_{n_{k}}-T x_{n_{k}}\right\|=0
$$

and

$$
\left\|x^{*}-S x^{*}\right\|=\lim _{n_{k} \rightarrow \infty}\left\|x_{n_{k}}-S x_{n_{k}}\right\|=0 .
$$

This shows that $x^{*} \in F$. According to Theorem 1, the $\operatorname{limit}_{n \rightarrow \infty}\left\|x_{n}-x^{*}\right\|$ exists. Then

$$
\lim _{n \rightarrow \infty}\left\|x_{n}-x^{*}\right\|=\lim _{n_{k} \rightarrow \infty}\left\|x_{n_{k}}-x^{*}\right\|=0,
$$

which means that $\left\{x_{n}\right\}$ converges to $x^{*} \in F$. Thus the sequence $\left\{x_{n}\right\}$ converges strongly to a common fixed point of the mappings $S$ and $T$. This completes the proof.

Theorem 4. Let $E$ be a real Banach space satisfying Opial's condition and $K$ be a weakly compact subset of $E$ with $K+K \subset K$. Let $S: K \rightarrow K$ be a quasinonexpansive mapping and $T: K \rightarrow K$ be uniformly L-Lipschitzian asymptotically quasi-nonexpansive mapping in the intermediate sense such that $F=F(S) \cap F(T) \neq$ $\varnothing$. Let $\left\{\alpha_{n}\right\}$ and $\left\{\beta_{n}\right\}$ be sequences in $[\delta, 1-\delta]$ for some $\delta \in(0,1)$. Let $\left\{x_{n}\right\}$ be the sequence defined by (1.3) with the restrictions $\sum_{n=1}^{\infty}\left\|u_{n}\right\|<\infty$ and $\sum_{n=1}^{\infty}\left\|v_{n}\right\|<\infty$. Put

$$
G_{n}=\max \left\{\sup _{x \in K, q \in F}\left(\left\|T^{n} x-q\right\|-\|x-q\|\right) \vee 0, \forall n \geq 1\right\}
$$

such that $\sum_{n=1}^{\infty} G_{n}<\infty$. Suppose that $S$ and $T$ have a hybrid fixed point, $I-S$ and $I-T$ are demiclosed at zero and $\left\{x_{n}\right\}$ is an approximating fixed point sequence 
for $S$ and $T$, that is, $\lim _{n \rightarrow \infty}\left\|x_{n}-S x_{n}\right\|=0$ and $\lim _{n \rightarrow \infty}\left\|x_{n}-T x_{n}\right\|=0$. Then $\left\{x_{n}\right\}$ converges weakly to a common fixed point of $S$ and $T$.

Proof. First, we show that $\omega_{w}\left(x_{n}\right) \subset F$. Let $x_{n_{k}} \rightarrow x$ weakly. By assumption, we have $\lim _{n \rightarrow \infty}\left\|x_{n}-S x_{n}\right\|=0$ and $\lim _{n \rightarrow \infty}\left\|x_{n}-T x_{n}\right\|=0$. Since $I-S$ and $I-T$ are demiclosed at zero, $x \in F$. By Opial's condition, $\left\{x_{n}\right\}$ possesses only one weak limit point, that is, $\left\{x_{n}\right\}$ converges weakly to a common fixed point of $S$ and $T$. This completes the proof.

Remark 2. Our results extend, improve and generalize many known results from the existing literature to the case of more general class of mappings and modified two-step iteration scheme with errors considered in this paper.

\section{CONCLUSION}

We proved several results on the iteration scheme (1.3) for a pair of quasi-nonexpansive and asymptotically quasi-nonexpansive mapping in the intermediate sense. This class is more general than the classes of nonexpansive, quasinonexpansive, asymptotically nonexpansive and asymptotically quasi-nonexpansive mappings. Thus our results provide improvements and extensions of the results of the existing literature.

\section{REFERENCES}

[1] R. Agarwal, D. O'Regan, and D. Sahu, "Iterative construction of fixed points of nearly asymptotically nonexpansive mappings," Nonlinear Convex Anal., vol. 8, no. 1, pp. pp. 61-79, 2007.

[2] C. Chidume and B. Ali, "Weak and strong convergence theorems for finite families of asymptotically nonexpansive mappings in Banach spaces," J. Math. Anal. Appl., vol. 330, pp. pp. 377-387, 2007.

[3] G. Das and J. Debate, "Fixed points of quasi-nonexpansive mappings," Indian J. Pure Appl. Math., vol. 17, pp. pp. 1263-1269, 1986.

[4] K. Goebel and W. Kirk, "A fixed point theorem for asymptotically nonexpansive mappings," Proc. Amer. Math. Soc., vol. 35, no. 1, pp. pp. 821-829, 1972.

[5] S. H. Khan, Y. Cho, and M. Abbas, "Convergence to common fixed points by a modified iteration process." J. Appl. Math. Comput., vol. 35, no. 1-2, pp. 607-616, 2011.

[6] S. Khan and W. Takahashi, "Approximating common fixed points of two asymptotically nonexpansive mappings," Sci. Math. Jpn., vol. 53, no. 1, pp. pp. 143-148, 2001.

[7] S. Khan and H. F. ud din, "Weak andstrong convergence of a scheme with errors for two nonexpansive mappings," Nonlinear Anal., vol. 61, no. 8, pp. pp. 1295-1301, 2005.

[8] Z. Opial, "Weak convergence of the sequence of successive approximations for nonexpansive mappings," Bull. Amer. Math. Soc., vol. 73, pp. pp. 591-597, 1967.

[9] M. Osilike and S. Aniagbosor, "Weak and strong convergence theorems for fixed points of asymptotically nonexpansive mappings," Math. and Computer Modelling, vol. 32, pp. pp. 1181-1191, 2000.

[10] B. Rhoades, "Fixed point iteration for certain nonlinear mappings," J. Math. Anal. Appl., vol. 183, pp. pp. 118-120, 1994.

[11] J. Schu, "Iterative construction of fixed points of asymptotically nonexpansive mappings," J. Math. Anal. Appl., vol. 158, pp. pp. 407-413, 1991. 
[12] J. Schu, "Weak and strong convergence to fixed points of asymptotically nonexpansive mappings," Bull. Austral. Math. Soc., vol. 43, no. 1, pp. pp. 153-159, 1991.

[13] N. Shahzad and A. Udomene, "Approximating common fixed points of two asymptotically quasi nonexpansive mappings in Banach spaces," Fixed point Theory and Applications, vol. 2006, Article ID 18909, pp. pp. 1-10, 2006.

[14] W. Takahashi and T. Tamura, "Convergence theorems for a pair of nonexpansive mappings," $J$. Convex Anal., vol. 5, no. 1, pp. pp. 45-56, 1998.

[15] K. Tan and H. Xu, "Approximating fixed points of nonexpansive mappings by the Ishikawa iteration process," J. Math. Anal. Appl., vol. 178, pp. pp. 301-308, 1993.

[16] B. Xu and M. Noor, "Fixed point iterations for asymptotically nonexpansive mappings in Banach spaces," J. Math. Anal. Appl., vol. 267, no. 2, pp. pp. 444-453, 2002.

[17] Y. Yao and Y. Liou, "New iterative schemes for asymptotically quasi-nonexpansive mappings," Journal of Inequalities and Applications, vol. 2010, Article ID 934692, pp. pp. 1-9, doi:10.1155/2010/934 692, 2010.

Author's address

G. S. Saluja

Department of Mathematics, Govt. Nagarjuna P.G. College of Science, Raipur - 492010 (C.G.), India.

E-mail address: saluja_19630rediffmail.com, saluja1963@gmail.com 